\title{
Hearing screening in a neonatal intensive care unit
}

\author{
Gisele M. L. Lima, ${ }^{1}$ Sérgio T. M. Marba, ${ }^{2}$ Maria Francisca C. Santos ${ }^{3}$
}

\begin{abstract}
Objective: Investigate the prevalence of hearing impairment in newborns hospitalized at the Intensive and Intermediate Care Unit at the Women's Comprehensive Health Center Neonatology Service (UNICAMP) and associated risk factors.

Methods: 979 newborn babies were assessed between January 2000 and January 2003, through automated auditory brainstem response (AABR) (ALGO 2e color screener). The result was considered normal when the newborn showed response to a 35dBNA signal bilaterally. The prevalence of AABR impairment and the odds ratio were analyzed with a $95 \%$ confidence interval using bivariate analysis. To identify the independent risk factors for hearing alterations, multivariate analyses were used with logistic regression.

Results: The prevalence of AABR impairment was $10.2 \%$, of which $5.3 \%$ was unilateral and $4.9 \%$ bilateral. From the multivariate analyses, the following observations were made: family history of congenital hearing loss $(O R=5.192 ; p=0.016)$, craniofacial deformity $(O R=5.530 ; p<0.001)$, genetic syndromes associated with hearing loss $(\mathrm{OR}=4.212 ; \mathrm{p}<0.001)$, weight below $1,000 \mathrm{~g}(\mathrm{OR}=3.230 ; \mathrm{p}<0.001)$, asphyxia $(\mathrm{OR}=3.532$; $p<0.001)$, hyperbilirubinemia $(O R=4.099 ; p=0.002)$ and use of mechanical ventilation $(O R=1.826 ; p<0.031)$ were the indicators that best characterized the group at risk for hearing impairment.

Conclusions: The prevalence of hearing impairment using AABR is high. Therefore, it is essential for all newborns who present isolated or associated risk factors to undergo hearing screening in situations in which it is not possible to have universal hearing screening.
\end{abstract}

J Pediatr (Rio J). 2006;82(2):110-4: Newborn, diagnosis, hearing loss.

\section{Introduction}

Hearing is the means by which the newborn comes into contact with the world of sound and with language structures. It is through oral language that humans are able to make contact with their fellowmen, and develop the ability to share their experiences, thoughts and ideas in the search for new knowledge. ${ }^{1}$

1. Mestre, Faculdade de Ciências Médicas, Universidade Estadual de Campinas (UNICAMP), Campinas, SP, Brasil. Médica neonatologista.

2. Doutor. Professor, Departamento de Pediatria, Faculdade de Ciências Médicas, UNICAMP, Campinas, SP, Brasil. Diretor, Área de Neonatologia, Centro de Assistência Integral à Saúde da Mulher (CAISM), UNICAMP, Campinas, SP, Brasil.

3. Doutora. Professora, Curso de Fonoaudiologia, Faculdade de Ciências Médicas e Centro de Estudos e Pesquisas em Reabilitação Gabriel Porto, UNICAMP, Campinas, SP, Brasil.

Partial financial support: FAPESP.

Manuscript received Jun 27 2005, accepted for publication Nov 022005.

Suggested citation: Lima GM, Marba ST,Santos MF. Hearing screening in a neonatal intensive care unit. J Pediatr (Rio J). 2006;82:110-4.
Bilateral hearing loss presents high incidence, affecting around 3 out of every 1,000 live births, and from 2 to 4 out of every 100 newborns leaving the neonatal intensive care unit (NICU). The initial signs of hearing loss are very subtle and systematic neonatal hearing screening is the most effective means of early detection. Early diagnosis and immediate intervention are decisive factors in the development and prognosis of these children. ${ }^{2-5}$

The hearing loss risk indicators, as well as the use of objective methods for performing hearing screening and follow-up were established and reviewed by the Joint Committee on Infant Hearing (JCIH). ${ }^{6}$ In Brazil, The Brazilian Committee on Hearing Loss in Childhood recommends neonatal hearing screening. ${ }^{7}$

Screening procedures may be divided into two categories: behavioral and electrophysiologic assessments. Behavioral techniques, due to the relative subjectivity of the assessment and difficulty in detecting mild or unilateral losses, determine a high number of false negative results. ${ }^{8}$ 
Electrophysiologic procedures have greater sensitivity and specificity, and the following may be used: auditory brainstem response (ABR), automated auditory brainstem response (AABR) and evoked oto-acoustic emissions (EOAE). ${ }^{9,10}$ Various studies have analyzed the cost of hearing screening in the neonatal period as well as the difference between the methods available. ${ }^{11,12}$

The objective of the present study was to assess the prevalence of hearing impairment by AABR in newborns admitted to an intensive and intermediate care unit and analyze the associated risk factors.

\section{Methods}

An observational cross-sectional study was conducted between January 2000 and January 2003. All the newborns admitted to the ICU and Neonatal Intermediate Care Unit at the Comprehensive Women's Health Assistance Center (School of Medical Sciences, UNICAMP, Brazil), whose admission lasted for over 48 hours, were included in the study. At the time of discharge from the hospital, they were submitted to hearing assessment by means of AABR using the ALGO Model 2e color - Natus screener.

The test was performed in a silent room, reserved for this purpose within the unit, by the researcher, with the child in a state of natural sleep in a common crib. The equipment sends approximately 1,000 clicks at $35 \mathrm{~dB}$ by means of phones placed over the newborns' ears, and after comparing the response obtained with an internal normal response model, automatically sends the objective pass/fail result, with statistical confidence of $99.96 \%$. The result was considered normal when the newborn responded to a $35 \mathrm{~dB}$ signal bilaterally and impaired when it did not present response to $35 \mathrm{~dB}$ in at least one ear.

After the test, a pre-coded card was filled out, using data from the newborn's case history record. The population was characterized as follows: birthweight, gestational age (by the Capurro or New Ballard method), weight for gestational age (Denver Curve and classification according to Battaglia and Lubchenco), sex, family history of congenital hearing loss and consanguinity. The presence of the following neonatal pathologies was investigated: craniofacial malformations, neonatal asphyxia (defined by the presence of three of more of the following characteristics: Apgar score at 5 minutes < 6; umbilical cord blood $\mathrm{pH}<7.10$; hypoxicischemic encephalopathy; systemic involvement), genetic syndromes, congenital infections, peri intraventricular hemorrhage, bacterial meningitis, and hyperbilirubinemia (total bilirubin $\geq 20 \mathrm{mg} / \mathrm{dl}$ for all newborns). Specialized procedures: use of phototherapy for more than two days, use of an incubator for more than five days, use of ototoxic medication for more than five days and mechanical ventilation for more than five days.

The data contained in the pre-coded card were introduced into a data file on a microcomputer in EpiInfo 6.0 .

The prevalence of hearing impairment and the odds ratio were analyzed with a confidence interval of $95 \%$ using bivariate analysis. To identify the independent risk factors for impaired $A A B R$, a multiple analysis was done with a logistic regression model, including all the variables of the bivariate analysis and a stepwise variable selection process, using the SAS system for Windows, version 8.2 (SAS Institute Inc, 1999-2001, Cary, NC, USA).

The protocol was assessed and approved by the Research Ethics Committee of the MSF/UNICAMP.

\section{Results}

Nine hundred and seventy-nine newborns were assessed, 494 (50.4\%) being boys and 485 (49.6\%) girls. One hundred $(10.2 \%)$ of the newborns failed in the hearing screening, $55(11.3 \%)$ being girls and $45(9.1 \%)$ being boys ( $p=0.2535)$. Involvement was bilateral in 48 newborn and unilateral in 52 .

The bivariate analysis revealed a statistically significant association between family history of congenital hearing loss and impaired AABR results, as well as for weight lower than $1,000 \mathrm{~g}$, presence of genetic syndrome, asphyxia, presence of craniofacial malformation, occurrence of meningitis, use of ototoxic medication for more than five days and mechanical ventilation for more than five days (Table 1).

According to the multivariate logistic regression model, the main characteristics of the group of children at greater risk of presenting with impaired hearing screening were as follows: family history of congenital hearing loss; craniofacial malformation; weight $<1,000 \mathrm{~g}$; mechanical ventilation for more than five days; hyperbilirubinemia and genetic syndrome (Table 2 ).

\section{Discussion}

The prevalence of bilateral hearing impairment was $4.9 \%$ and of at least one compromised ear was $10.2 \%$. Analysis of these data must take into account the method used. The method used in this study, the AABR done with the ALGO 2e Natus device, represents a simplification of the conventional $A B R$, which automatically incorporates response detection and comparison with a "normal" model obtained from a large population sample of newborns. Therefore, it does not need to be interpreted by the examiner. The method employed in the present study had a sensitivity of 98 to $100 \%$ and high specificity, $97 \%, 13-15$ 
so that the prevalence of failure in the neonatal hearing screening test must be understood as possible hearing loss, and false negatives may be linked with incomplete myelinization in the studied age group. The diagnosis must be confirmed with the conventional $A B R$, considering the maturation of the Central Nervous System. ${ }^{16}$

A study conducted in Germany found $5 \%$ of children with impaired $A A B R, 2 \%$ bilaterally. ${ }^{17}$ In another study conducted in an NICU with the use of two-stage AABR, 8\% and $3.1 \%$ failed the screening test, and confirmation of the diagnosis by conventional ABR was obtained in $2.5 \%$. The exam performed close to hospital discharge had with greater specificity. ${ }^{18}$

In Brazil, a universal screening study using transient evoked otoacoustic emissions detected $1.8 \%$ of impairment in the exam and confirmed hearing loss in $2.3 / 1,000$

Table 1 - Bivariate analysis of the variables associated with the result of neonatal hearing screening $(\mathrm{n}=979)$

\begin{tabular}{|c|c|c|c|c|c|}
\hline Variable & n (\%) & Normal & Impaired & OR (95\%CI) & $\mathbf{p}$ \\
\hline \multicolumn{6}{|l|}{ Neonatal characteristics } \\
\hline Family history & $13(1.3)$ & 9 & 4 & $4.03(1.22-13.33)$ & 0.022 \\
\hline Consanguinity & $7(0.7)$ & 5 & 2 & $3.57(0.68-8.64)$ & 0.131 \\
\hline Weight $<1,000 \mathrm{~g}$ & $50(5.1)$ & 39 & 11 & $2.51(1.20-5.22)$ & 0.014 \\
\hline Weight $1,000-2,500 \mathrm{~g}$ & $454(46.4)$ & 413 & 41 & $2.51(1.20-5.22)$ & 0.579 \\
\hline Gestational age $\leq 30$ weeks & $75(7.7)$ & 63 & 12 & $1.57(0.79-3.13)$ & 0.196 \\
\hline Gestational age 31-34 weeks & $267(27.3)$ & 248 & 19 & $0.63(0.36-1.10)$ & 0.106 \\
\hline Gestational age 35-36 weeks & $201(20.5)$ & 179 & 22 & $1.01(0.59-1.73)$ & 0.957 \\
\hline Small for gestational age & $209(21.3)$ & 188 & 21 & $0.98(0.59-1.63)$ & 0.937 \\
\hline Large for gestational age & $47(4.8)$ & 42 & 5 & $1.04(0.40-2.72)$ & 0.929 \\
\hline Girls & $485(49.6)$ & 430 & 55 & $1.27(0.84-1.93)$ & 0.254 \\
\hline \multicolumn{6}{|l|}{ Neonatal pathologies } \\
\hline Craniofacial malformation & $104(10.6)$ & 74 & 30 & $4.66(2.86-7.60)$ & $<0.001$ \\
\hline Genetic syndrome & $42(4.3)$ & 28 & 14 & $4.95(2.51-9.75)$ & $<0.001$ \\
\hline Hyperbilirubinemia (TB $\geq 20$ mg/dl) & $42(4.3)$ & 35 & 7 & $1.81(0.78-4.20)$ & 0.164 \\
\hline $\mathrm{PIH}$ & $33(3.4)$ & 29 & 4 & $1.22(0.42-3.55)$ & 0.713 \\
\hline Asphyxia & $81(8.3)$ & 64 & 17 & $2.61(1.46-4.66)$ & 0.001 \\
\hline Congenital infection & $103(10.5)$ & 95 & 8 & $0.72(1.20-5.22)$ & 0.388 \\
\hline Meningitis & $20(2.0)$ & 15 & 5 & $3.03(1.08-8.53)$ & 0.035 \\
\hline \multicolumn{6}{|l|}{ Specialized procedures } \\
\hline Ototoxic medication $>5$ days & $213(21.7)$ & 181 & 32 & $1.81(1.16-2.85)$ & 0.009 \\
\hline Incubator $>5$ days & $317(32.4)$ & 285 & 32 & $0.98(0.63-1.53)$ & 0.932 \\
\hline Phototherapy $>2$ days & $387(39.5)$ & 345 & 42 & $1.17(0.77-1.78)$ & 0.465 \\
\hline Mechanical ventilation $>5$ days & $200(20.4)$ & 169 & 31 & $1.88(1.20-2.98)$ & 0.006 \\
\hline
\end{tabular}

$\mathrm{Cl}=$ confidence interval $\mathrm{OR}=$ odds ratio $\mathrm{PIH}=$ peri intraventricular hemorrhage; $\mathrm{TB}=$ total bilirubin.

Table 2 - Multiple analysis by logistic regression of the risk factors for impaired hearing screening

\begin{tabular}{lccccc}
\hline Variable & Estimate & Error & p & OR & 95\%CI \\
\hline Craniofacial malformation & 1.710 & 0.283 & $<0.001$ & 5.530 & $3.177 ; 9.627$ \\
Positive family history & 1.647 & 0.681 & 0.016 & 5.192 & $1.365 ; 19.744$ \\
Positive genetic syndrome & 1.438 & 0.391 & $<0.001$ & 4.212 & $1.958 ; 9.061$ \\
Hyperbilirubinemia & 1.411 & 0.465 & 0.002 & 4.099 & $1.648 ; 10.199$ \\
Positive asphyxia & 1.262 & 0.321 & $<0.001$ & 3.532 & $1.883 ; 6.624$ \\
Weight $<1,000 \mathrm{~g}$ & 1.172 & 0.447 & 0.009 & 3.230 & $1.344 ; 7.759$ \\
Mechanical ventilation $>$ 5 days & 0.602 & 0.279 & 0.031 & 1.826 & $1.057 ; 3.155$ \\
\hline
\end{tabular}

$\mathrm{Cl}=$ confidence interval; OR $=$ odds ratio. 
newborns. ${ }^{19}$ Another study assessed newborns weighing under $1,500 \mathrm{~g}$ with distortion product otoacoustic emissions and found a prevalence of $6.3 \%$ for hearing loss. ${ }^{20}$

Although the data in the literature show variable results, the prevalence we observed is above the average, which may be related to the characteristics of the present group, comprised of newborns admitted to the intensive and intermediate care unit at a University Hospital that is a regional excellence center and therefore provides care to highly complex cases. Thus, a higher prevalence of hearing loss in the population treated at this facility can be expected.

Family history of congenital hearing loss was identified in the bivariate analysis as a factor significantly associated with hearing impairment. This shows that among the sensorineural deficiencies of known etiology, those of a hereditary origin are highly representative. With the advances in the field of molecular genetics, new genes responsible for sensorineural deafness have been identified, and the mechanisms involving cases of deafness due to non-syndromic causes have been explained in such a way that the influence of this variable may be better understood in the future. $18,21,22$

Since birthweight is a continuous variable, it was separately analyzed in the following categories: $<1,000 \mathrm{~g}$, from 1,000 to $1,500 \mathrm{~g}$, from 1,501 to $2,500 \mathrm{~g}$ and $>2,500 \mathrm{~g}$. Newborns weighing $>2,500 \mathrm{~g}$ were considered to be at less risk, and were considered as the reference category, with which the other categories were compared. A significant association was noted in newborns $<1,000 \mathrm{~g}$. Weight from 1,000 to $1,500 \mathrm{~g}$, as well as from 1,501 to $2,500 \mathrm{~g}$ were not a significant risk factor. The current literature considers weight $<1,500 \mathrm{~g}$ to be a risk factor, although this finding is not consistent and its greater or lesser significance depends on the differences in the populations assessed, as well as the conditions of perinatal care. 17,22

The presence of craniofacial malformations was shown to be significantly related to hearing impairment and has been a frequent finding in the literature. In different studies, this variable is responsible for between 11 and $16 \%$ of the cases of hearing loss, increasing the risk of these children presenting with impairment by up to 5 times. $17,23,24$

In the literature, syndromes associated with sensorineural deafness, as well as structural defects with or without chromosomal abnormalities, have been described as a risk factor, which is in agreement with the results found in the present study, in which the presence of the genetic syndrome was significantly associated with greater risk of hearing impairment. 22,24

As regards comorbidities, asphyxia was associated with 3.5 times more risk of hearing impairment. Although the brain is more sensitive to anoxia than the auditory system, severe hypoxic ischemic encephalopathy was an important risk factor for hearing loss. In current literature, these results also varied in accordance with the studied population and mainly with the definition of neonatal asphyxia. ${ }^{16,21}$ Nevertheless, the impact of asphyxia on hearing may be minimized or abolished if it is controlled, which may be achieved by training the teams that give assistance to newborns in the delivery room. 25

In spite of a declining trend in the occurrence of meningitis in the neonatal period, in the present studied it was identified as being significantly associated with hearing impairment in the bivariate analysis, which is in agreement with the literature. However, in the multiple analysis, in which we attempted to eliminate the joint action of various other factors, this association was not maintained. 17,26

As regards hyperbilirubinemia, the data in the literature point it out as an important cause of deafness. ${ }^{27}$ In the present study assessment, it was not identified as a risk factor in the bivariate analysis. However, when analyzed in conjunction with the other variables, it acquired great statistical power, becoming an important event in the occurrence of hearing impairment.

These results suggest that it is necessary to implement protocols with strict control of cases of jaundice, including objective measures for assessing the serum level of bilirubin and highly efficient phototherapy, which represent measures to prevent hearing impairment resulting from hyperbilirubinemia.

Although the use of phototherapy has not been the object of study in the literature, this analysis was made because it is a very common procedure in our unit, and involves a noise level above the ideal proposed (mean of $45 \mathrm{~dB}$ during the day and $35 \mathrm{~dB}$ at night, the maximum limit suggested being $58 \mathrm{~dB}$ ). ${ }^{29}$ The number of children submitted to phototherapy is higher than the number considered as having hyperbilirubinemia, since the indication of phototherapy contemplates other children in addition to those with total bilirubin $\geq 20 \mathrm{mg} / \mathrm{dl}$. We did not observe an association between this variable and hearing impairment.

The literature considers the use of ototoxic medication to be an important risk factor for deafness in the neonatal period. In the present case series, a significant relationship was observed in the bivariate analysis, which was not maintained in the multiple analysis. It should be noted that the drug of choice for the treatment of gram negative organisms at our institution is amikacin, and we believe that a strict control of the serum dose of this drug is an important measure for preventing hearing loss due to ototoxicity. It may be speculated that improvement in the treatment in NICUs may reduce the probability of auditory involvement. 30 
Mechanical ventilation for more than five days showed a significant association with hearing impairment. Various aspects have been related to the greater occurrence of deafness in children submitted to assisted ventilation, including the noise level of the appliances, duration of mechanical ventilation, and the pulmonary pathologies involved.

From the multiple analysis, a subset of variables was obtained, which better characterizes the group at risk of hearing impairment; presence of family history, craniofacial malformation, genetic syndrome, hyperbilirubinemia, asphyxia, weight $<1,000 \mathrm{~g}$ and mechanical ventilation for more than five days, so that these risk factors may direct a systematic assessment, until universal screening becomes possible.

\section{References}

1. Lewis DR. As habilidades auditivas do recém-nascido e a triagem auditiva neonatal. In: Andrade CRF. Fonoaudiologia em berçário normal e de risco. São Paulo: Lovise; 1996. p. 149-68.

2. Downs MP, Yoshinaga-Itano $C$. The efficacy of early identification and intervention for children with hearing impairment. Pediatr Clin North Am. 1999;46:79-87.

3. American Academy of Pediatrics. Task Force on Newborn and Newborn and Infant Hearing. Newborn and infant hearing loss: detection and intervention. Pediatrics. 1999;103:527-30.

4. Kenna MA. Neonatal hearing screening. Pediatr Clin North Am. 2003;50:301-13.

5. Moeller MP. Early intervention and language development in children who are deaf and hard of hearing. Pediatrics. 2000;106:e43.

6. American Academy of Pediatrics. Joint Committee on Infant Hearing. Year 2000 position statement: principles and guidelines for early hearing detection and intervention programs. Pediatrics. 2000;106:798-817.

7. Comitê Brasileiro sobre Perdas Auditivas na Infância. Recomendação 01/99 do Comitê Brasileiro sobre Perdas Auditivas na Infância. Jornal do Conselho Federal de Fonoaudiologia. 2000;3-7.

8. Bassetto MCA. Triagem auditiva em berçário. In: Bassetto MCA, Brock R, Wajnsztejn R. Neonatologia - um convite à atuação fonoaudiológica. São Paulo: Lovise; 1995. p. 289-93.

9. Matas CG. Medidas eletrofisiológicas da audição - audiometria de tronco cerebral. In: Carvalho RMM. Fonoaudiologia: informação para a formação. Rio de Janeiro: Guanabara Koogan; 2003. p. 43-57.

10. Carvalho RMM. Emissões otoacústicas: conceitos básicos e aplicações. In: Carvalho RMM. Fonoaudiologia: informação para a formação. Rio de Janeiro: Guanabara Koogan; 2003. p. 22-41.

11. National Center for Hearing Assessment and Management. What does a newborn hearing screening program cost? http:// www. infanthearing.org/resources/cost/index.html. Access: $23 / 06 / 2005$

12. Keren R, Helfand M, Homer C, McPhillips H, Lieu TA. Projected cost-effectiveness of statewide universal newborn hearing screening. Pediatrics. 2002;110:855-64.
13. Oudesluys-Murphy AM, Bhoalsingh $R$, Van Zanten GA, Van Straaten HLM. Neonatal hearing screening. Eur J Pediatr. 1996;155:429-35.

14. Doyle KJ, Fujikawa S, Rogers P, Newman E. Comparison of newborn hearing screening by transient otoacoustic emissions and automated auditory brainstem response using ALGO-2O. Int J Pediatr Otorhinolaryngol. 1998;43:207-11.

15. Van Straaten HL. Automated auditory brainstem response in neonatal hearing screening. Acta Paediatr Suppl. 1999;88:76-9.

16. Northern JL, Downs MP. Audição em crianças. $5^{a}$ ed. Rio de Janeiro: Guanabara Koogan; 2005

17. Meyer C, Witte J, Hildmann A, Hennecke KH, Schunck KU, Maul $\mathrm{K}$, et al. Neonatal screening for hearing disorders in infant at risk: incidence, risk factors and follow-up. Pediatrics. 1999;104:900-4

18. van Straaten HLM, Hille ET, Kok JH, Verkerk PH. Dutch NICU Neonatal Hearing Screening Working Group. Implementation of a nation-wide automated auditory brainstem response hearing screening program in neonatal intensive care units. Acta Paediatr. 2003; $92: 332-8$.

19. Chapchap MJ, Segre CM. Universal newborn hearing screening and transient evoked otoacoustic emission: new concepts in Brazil. Scand Audiol Suppl. 2001;53:33-6.

20. Uchôa NT, Procianoy RS, Lavinsky L, Sleifer P. Prevalência de perda auditiva em recém-nascidos de muito baixo peso. J Pediatr (Rio J). 2003;79:123-8.

21. Kitamura K, Takahashi K, Tamagawa Y, Noguchi Y, Kuroishikawa Y, Ishicawa K, et al. Deafness genes. J Med Dent Sci. 2000;47: $1-11$.

22. Chu K, Elimian A, Barbera J, Ogburn P, Spitzer A, Quirk JG. Antecedents of newborn hearing loss. Obstet Gynecol. 2003; 101:584-8.

23. Watkin PM, Baldwin M, Mcenery G. Neonatal at risk screening and the identification of deafness. Arch Dis Child. 1991;66:1130-5.

24. Homer JJ, Linney SL, Strachan DR. Neonatal hearing screening using the auditory brainstem response. Clin Otolaryngol. 2000;25:66-70.

25. American Academy of Pediatrics, American Heart Association. International guideline for neonatal resuscitation: an excerpt from the guideline 2000 for cardiopulmonary resuscitation and emergency cardiovascular care: international consensus on science. http://www.pediatrics.org/cgi/content/full/106/3/e29. Access: 23/06/2005.

26. Roizen NJ. Non-genetic causes of hearing loss. Ment Retard Dev Disabil Res Rev. 2003;9:120-7.

27. Oysu C, Aslan I, Ulubil A, Baserer N. Incidence of cochlear involvement in hyperbilirubinemic deafness. Ann Otol Rhinol Laryngol. 2002;111:1021-5.

28. Facchini FP. Icterícia neonatal. In: Marba STM, Mezzacappa F, editores. Manual de neonatologia da UNICAMP. Rio de Janeiro: Revinter; 1998. p. 59-64.

29. American Academy of Pediatrics. Noise: a hazard for the fetus and newborn. Pediatrics. 1997;100:724-7.

30. Hess M, Finckh-Kramer U, Bartsch M, Kewitz G, Versmold $H$, Gross $M$. Hearing screening in at-risk neonate cohort. Int J Pediatr Otorhinolaryngol. 1998;46:81-9.

Correspondence:

Gisele Marafon Lopes de Lima

Rua Coronel Quirino, 1343/72

CEP 13025-002 - Campinas, SP - Brazil

Tel./Fax: +55 (19) 3294.9573

E-mail: marafon@supernet.com.br 